\title{
Capital Structure and International Debt Shifting: A Comment
}

\author{
Jarle Møen* $\quad$ Dirk Schindler ${ }^{\dagger} \quad$ Guttorm Schjelderup ${ }^{\ddagger}$
}

August 2008

\begin{abstract}
In a recent article, Huizinga, Laeven and Nicodème (2008) present a novel model that motivates an extensive empirical analysis of international debt shifting. We point out that the model fails to account for internal debt, and that once internal debt is properly accounted for, the external debt mechanism they propose is not identified in the empirical analysis. We also point out that affiliate specific debt costs reduce affiliate dividends. When this is implemented in the model, their regression equation can only be derived under the very restrictive assumption that effective tax rates on dividends are the same in all countries.
\end{abstract}

JEL Codes: F23, G32, H25

*Department of Finance and Management Science, Norwegian School of Economics and Business Administration. Email: jarle.moen@nhh.no.

${ }_{\dagger}^{\dagger}$ Department of Economics, Universität Konstanz. Email: dirk.schindler@unikonstanz.de.

${ }^{\ddagger}$ Corresponding author. Department of Finance and Management Science, Norwegian School of Economics and Business Administration, Helleveien 30, N-5045 Bergen, Norway. Email: guttorm.schjelderup@nhh.no.

Konstanzer Online-Publikations-System (KOPS)

URN: http://nbn-resolving.de/urn:nbn:de:bsz:352-opus-88855

URL: http://kops.ub.uni-konstanz.de/volltexte/2009/8885 


\section{Introduction}

In a recent article Huizinga, Laeven and Nicodème (2008) (henceforth HLN) present a novel model that motivates an extensive empirical analysis of international debt shifting. They report their findings by stating: “..stronger incentives for debt finance in one country encourage debt finance in that country but at the same time discourage debt finance in other countries to keep the overall indebtedness of the multinational in check" (4th paragraph on p. $81)$.

This theoretical result is derived under two problematic assumptions. The first is that internal debt is not part of the firm's financing structure. A main insight in the corporate finance literature is that internal debt and equity are equivalent except for tax purposes, and that it is optimal for a multinational firm (MNC) to use internal debt as part of a tax-efficient debt structure. The importance of this mechanisms is also documented in a series of empirical papers. ${ }^{1}$ Their second assumption is that incentive related debt costs that affiliates incur do not affect affiliate dividends available for repatriation. It is well known that in a static model as in HLN, net cash-flow available for repatriation as a dividend in an affiliate consists of economic profit plus the return to equity minus tax payments (see Sinn 1987, p. 66). Thus, since economic profit is diminished by affiliate specific debt costs, such costs do indeed reduce affiliate dividend payments. We show that (i) If the first assumption is relaxed so that internal debt is allowed, the effect of the external debt mechanism in HLN is not identified. It is in fact likely that the empirical results in the paper are driven by internal debt shifting. (ii) If the second assumption is corrected, their regression equation (5) can only be derived if effective tax rates on dividends are the same in all countries. To make these points more rigorous, we present a brief model.

\footnotetext{
${ }^{1}$ See Mintz and Smart (2004), Desai, Foley, and Hines (2004), Mintz and Weichenrieder (2005), Büttner et al (2006) and Büttner and Wamser (2007).
} 


\section{The model}

Following HLN a multinational firm is domiciled in country $p$, but has affiliates in $i=1, \ldots, n$ countries. Each affiliate has fixed assets $A_{i}$ and for the purpose of exposition we shall let this asset be capital used to produce a homogenous good by the production function $y_{i}=f\left(A_{i}\right)$. Rental costs of capital are exogenous (small country assumption) and equal to $r$. Capital $A_{i}$ is financed either by equity $I_{i}$, external (third party) debt $L_{i}$, or internal debt $\hat{L}_{i}$ from related affiliates. The inclusion of internal debt is a new feature we add to the HLN-model. The balance sheet of affiliate $i$ can be stated as $A_{i}=I_{i}+L_{i}+\hat{L}_{i}$, and the balance sheet of the MNC is $\sum_{i \neq p} I_{i}=E_{p}+L_{p}+\hat{L}_{p}$. Following HLN the cost function of external debt is

$$
C\left(\lambda_{i}\right)=\frac{\mu}{2} \cdot\left(\lambda_{i}-\lambda^{*}\right)^{2} \cdot A_{i}+\frac{\mu}{2} \cdot\left(\lambda^{*}\right)^{2} \cdot A_{i},
$$

where $\lambda^{*}$ is the optimal leverage ratio in absence of taxation, $\lambda_{i}=L_{i} / A_{i}$ is the leverage ratio of external debt in affiliate $i$, and $\mu>0$ is a cost parameter.

Internal debt costs may accrue due to the need to circumvent thincapitalization and controlled-foreign-company rules, say, and we assume in line with the literature on internal debt that the cost function is given by

$$
\hat{C}\left(\hat{\lambda}_{i}\right)=\frac{\eta}{2} \cdot\left(\hat{\lambda}_{i}\right)^{2} \cdot A_{i} \text { if } \hat{\lambda}_{i}>0 \text { and } \hat{C}\left(\hat{\lambda}_{i}\right)=0 \text { if } \hat{\lambda}_{i} \leq 0
$$

where $\hat{\lambda}_{i}=\hat{L}_{i} / A_{i}$ is the leverage ratio of internal debt in affiliate $i$ and $\eta>0$ is a cost parameter. In line with HLN we define $\lambda_{f}=\sum_{i} L_{i} / \sum_{i} A_{i}$ as the firm wide leverage ratio for external debt, and follow them in that bankruptcy costs are proportional to the MNC's overall assets, as

$$
C_{f}=\frac{\gamma}{2} \cdot \lambda_{f}^{2} \cdot \sum_{i} A_{i}=\frac{\gamma}{2} \cdot \frac{\left(\sum_{i} L_{i}\right)^{2}}{\sum_{i} A_{i}}
$$

In order to make clear how HLN implicitly invoke symmetry assumptions 
on withholding taxes, let true and taxable profit in affiliate $i$ be $\pi_{i}^{e}$ and $\pi_{i}^{t}$, that is,

$$
\pi_{i}^{e}=f\left(A_{i}\right)-r \cdot A_{i}-C\left(\lambda_{i}\right)-\hat{C}\left(\hat{\lambda}_{i}\right), \quad \pi_{i}^{t}=f\left(A_{i}\right)-r \cdot\left(L_{i}+\hat{L}_{i}\right) .
$$

Following HLN, debt costs are not tax deductible, but as seen above they reduce true profit. As in HLN we let $V_{i}^{L}$ and $V_{i}^{U}$ be the values of a leveraged and a completely unleveraged affiliate in country $i$, and define $t_{i}$ as the statutory corporate tax rate in country $i$. Affiliate $i$ 's profit after corporate taxation in country $i$ is then

$$
\pi_{i}=\underbrace{\pi_{i}^{e}-t_{i} \cdot \pi_{i}^{t}}_{=V_{i}^{L}}=\underbrace{\left(1-t_{i}\right) \cdot f\left(A_{i}\right)-r \cdot A_{i}}_{=V_{i}^{U}}+t_{i} \cdot r \cdot\left(L_{i}+\hat{L}_{i}\right)-C\left(\lambda_{i}\right)-\hat{C}\left(\hat{\lambda}_{i}\right),
$$

where it is seen that affiliate specific debt reduces potential dividend payouts.

In a static one-period model as used by HLN, the value of a firm $\left(V^{L}\right)$ and the firm's after tax profit $\left(\Pi_{p}\right)$ are identical, and can be calculated by summing up profits across all affiliates. Following HLN, repatriated dividends $\pi_{i}$ can be subject to a non-resident withholding tax $\left(w_{i}^{e}\right)$, the parent tax rate $t_{p}$ on repatriated dividends (adjusted possibly for various credit schemes) and the corporate tax rate $t_{i}$. In HLN the effective tax rate on dividends is defined as $\tau_{i}$ and encompasses different combinations of these three taxes, depending on the system for taxing repatriated dividends. ${ }^{2}$ Equation (4) shows, however, that the corporate tax rate $t_{i}$ cannot be compounded in $\tau_{i}$ (as done in HLN), but is a function of $t_{p}$ and $w_{i}^{e}$ only. $^{3}$

The value of the firm can be written as $\Pi_{p}=V^{L}=\sum_{i} \tau_{i} \cdot V_{i}^{L}-C_{f}=\sum_{i} \tau_{i}$. $\pi_{i}-C_{f}$. Maximizing $\Pi_{p}$ taking into account that the overall sum of lending and borrowing from related companies must be equal to zero $\left(\sum_{i} r \cdot \hat{L}_{i}=0\right)$,

${ }^{2}$ See, e.g., page 87 where under the deduction system $\tau_{i}=1-\left(1-t_{p}\right)\left(1-w_{i}^{e}\right)\left(1-t_{i}\right)$.

${ }^{3}$ See Leechor and Mintz (1993) for a discussion of how $\tau_{i}$ also may depend on corporate policy. 
the maximization problem is

$$
\begin{aligned}
\max _{L_{i}, \hat{L}_{i}} \Pi_{p} & =\sum_{i} \tau_{i} \cdot\left\{\left(1-t_{i}\right) f\left(A_{i}\right)-r \cdot A_{i}+t_{i} \cdot r \cdot\left(L_{i}+\hat{L}_{i}\right)\right. \\
& \left.-\frac{\mu}{2} \cdot\left(\frac{L_{i}}{A_{i}}-\lambda^{*}\right)^{2} \cdot A_{i}-\frac{\mu}{2} \cdot\left(\lambda^{*}\right)^{2} \cdot A_{i}-\hat{C}\left(\hat{\lambda}_{i}\right)\right\}-\frac{\gamma}{2} \cdot \frac{\left(\sum_{i} L_{i}\right)^{2}}{\sum_{i} A_{i}} \\
\text { s.t. } & \sum_{i} r \cdot \hat{L}_{i}=0 .
\end{aligned}
$$

The resulting first order conditions are

$$
\begin{array}{ll}
L_{i}: & \tau_{i} \cdot\left\{t_{i} \cdot r-\mu \cdot\left(\frac{L_{i}}{A_{i}}-\lambda^{*}\right)\right\}-\gamma \cdot \frac{\sum_{i} L_{i}}{\sum_{i} A_{i}}=0, \\
\hat{L}_{i} \quad: \quad & \tau_{i} \cdot\left\{t_{i} \cdot r-\hat{C}^{\prime}\left(\hat{\lambda}_{i}\right) \cdot \frac{1}{A_{i}}\right\}-m \cdot r=0,
\end{array}
$$

where $m$ is the Lagrangian multiplier. From (6) it follows that

$$
\frac{\hat{C}^{\prime}\left(\hat{\lambda}_{i}\right)}{A_{i}}=r \cdot \frac{\tau_{i} \cdot t_{i}-m}{\tau_{i}} \text { and } m=\min _{i} t_{i}^{e}=\min _{i} \tau_{i} \cdot t_{i}=\tau_{1} \cdot t_{1}
$$

For illustrative purposes we number the countries such that country 1 has the lowest effective tax rate $t_{i}^{e}$. By applying $(2), \hat{\lambda}_{i}=\frac{r}{\eta} \cdot \frac{\tau_{i} \cdot t_{i}-\tau_{1} \cdot t_{1}}{\tau_{i}}>0$ in all affiliates $i>1$ and $\hat{\lambda}_{1}=\frac{-\sum_{i>1} \hat{L}_{i}}{A_{1}}<0$. This shows that it is profit maximizing for a multinational firm to use internal debt and that any analysis that omits internal debt does not model a tax-efficient financing structure.

Next, it can be shown from the first order condition (5) that only if all countries employ the same effective tax on repatriated dividends $\left(\tau_{i}=\tau_{j}\right.$, $i \neq j$ ), can the first order condition (5) in HLN, which is used as a basis for their regression equation (6) be derived. ${ }^{4}$ Applying the definitions given in HLN for $\beta_{k}, k=0,1,2$, correcting these for the proper effective withholding tax term, we have $\beta_{0}=\frac{\tau \cdot \mu}{\tau \cdot \mu+\gamma}, \beta_{1}=\frac{1}{\tau \cdot \mu+\gamma}$ and $\beta_{2}=\frac{\gamma}{\tau \cdot \mu+\gamma}$. Following the

${ }^{4}$ The full derivation is available in the technical appendix. 
same procedure as in HLN, we obtain

$$
\lambda_{i}=\beta_{0} \cdot \lambda^{*}+\beta_{1} \cdot r \cdot \tau \cdot t_{i}+\beta_{2} \cdot r \cdot \sum_{j \neq i}\left(t_{i}-t_{j}\right) \cdot \rho_{j}
$$

which corresponds to equation (5) in HLN if we set the interest rate $r=1$, an assumption they implicitly invoke. Defining $\beta_{3}=\frac{1}{\eta}$ and using $\tau_{i}=\tau_{j}=\tau$ again, the total leverage ratio $b_{i}=\lambda_{i}+\hat{\lambda}_{i}$ of an affiliate $i>1$ is

$$
b_{i}=\beta_{0} \cdot \lambda^{*}+\beta_{1} \cdot r \cdot \tau \cdot t_{i}+\beta_{2} \cdot r \cdot \sum_{j \neq i}\left(t_{i}-t_{j}\right) \cdot \rho_{j}+\beta_{3} \cdot r \cdot\left[t_{i}-t_{1}\right], \forall i>1,
$$

whilst the overall leverage ratio of the internal bank, $b_{1}=\lambda_{1}+\hat{\lambda}_{1}$, is

$$
b_{1}=\beta_{0} \cdot \lambda^{*}+\beta_{1} \cdot r \cdot \tau \cdot t_{1}+\beta_{2} \cdot r \cdot \sum_{j \neq 1}\left(t_{1}-t_{j}\right) \cdot \rho_{j}-\frac{\sum_{i>1} \hat{L}_{i}}{A_{1}} .
$$

\section{Interpretation of Empirical Results}

In the empirical application, HLN measure leverage as total leverage including internal debt. The equation they estimate is

$$
b_{p i t}=\alpha_{p}+\beta_{1} \cdot \tau_{p i t}+\beta_{2} \cdot \sum_{j \neq i}\left(\tau_{p i t}-\tau_{p j t}\right) \rho_{p j t}+\gamma \cdot X_{p i t}+\epsilon_{p i t},
$$

where $X$ represents various control variables and $\epsilon$ is an error term. The index pit is subsidiary $i$ of parent firm $p$ at time $t$. Parent firms are not included in their main sample, and data on subsidiaries outside Europe is unavailable. According to our revised version of their model they should have estimated

$b_{p i t}=\alpha_{p}+\beta_{1} r \cdot \tau t_{i t}+\beta_{2} r \cdot \sum_{j \neq i}\left(t_{i t}-t_{j t}\right) \rho_{p j t}+\beta_{3} r \cdot\left(t_{i t}-t_{p 1 t}\right)+\gamma \cdot X_{p i t}+\epsilon_{p i t}, \forall p i>p 1$ 
In this equation $t_{p 1 t}$ denotes the corporate tax rate of the subsidiary within the group facing the lowest corporate tax rate. We see immediately that the inclusion of $r$ demands some reinterpretation of their estimated coefficients. $^{5}$ Furthermore, the use of $\tau_{p i t}$ (as they define it) instead of $t_{i t}$ will cause an attenuation bias in $\beta_{2}$ due to measurement error in their main variable, $\sum_{j \neq i}\left(\tau_{p i t}-\tau_{p j t}\right) \rho_{p j t} \cdot{ }^{6}$ Regarding the sample, we see that it is the subsidiary in the low tax country that should have been excluded, rather than the parent firm.

We will put these issues aside and focus on the effect of the omitted variable $\left(t_{i t}-t_{p 1 t}\right)$. Both Desai, Foley, and Hines (2004), Mintz and Weichenrieder (2005), Büttner et al (2006) and Büttner and Wamser (2007) find that internal debt is sensitive to tax rates. It is therefore likely that this is an important explanatory variable for total leverage. Since $\left(t_{i t}-t_{p 1 t}\right) \approx$ $\left(\tau_{p i t}-\tau_{p 1 t}\right)$, and $\left(\tau_{i t}-\tau_{p 1 t}\right)$ is part of their main variable $\sum_{j \neq i}\left(\tau_{p i t}-\tau_{p j t}\right) \rho_{p j t}$, the omitted variable $\left(t_{i t}-t_{p 1 t}\right)$ will be positively correlated with their main variable. $^{7}$ This will cause a positive bias in the estimated $\beta_{2}$. Actually, it is quite possible that the effect HLN find of the differences between the national and foreign tax rates on leverage, is driven by internal debt rather than the external debt mechanism they model. ${ }^{8}$

It should be noted that HLN discuss internal debt in an extension to the empirical analysis. In order to explore the robustness of their results, they

${ }^{5}$ Assuming that $r=1$ as HLN implicitly do seems rather haphazardous.

${ }^{6}$ What happens to $\beta_{1}$ is harder to assess. $\tau_{p i t}$ is different from the "true" variable $\tau t_{i}$ coming out of the revised model, but this "true" variable builds on the inaccurate symmetry assumption $\tau_{i}=\tau_{j}$ for all $i$ and $j$.

${ }^{7}$ Note that $\left(t_{i t}-t_{p 1 t}\right)=\left(\tau_{p i t}-\tau_{p 1 t}\right)$ in cases where both the parent firm and the subsidiary belong to countries in the Euro-zone.

${ }^{8}$ The external debt mechanism they model depends on the assumption that parent firms provide explicit or implicit credit guarantees for the debt of all their subsidiaries. One motive of setting up a subsidiary in a foreign country may, however, be to limit the liability of the parent company. If this is common, the true $\beta_{2}$ will be small. On the other hand, $\left(t_{i t}-t_{p 1 t}\right)$, is unobservable in cases where MNCs have subsidiaries in tax havens outside Europe. This may weaken the omitted variable bias, although it also increases the measurement error in their main variable. 
construct a variable $\varphi_{i}$, capturing the relative tax advantage of internal debt versus equity. This variable is defined in their table 6 . It will in most cases be equal to $\left(t_{i}-t_{p}\right) .{ }^{9}$ They report the result of adding $\varphi_{i}$ to the regression in table 11, column (1). They do not find a significant effect of this variable and conclude that their main result is not affected by the incentive to use internal debt. It is, however, evident from our revised version of their model that this ad hoc procedure is ill-conceived since it is not the tax difference vis-a-vis the parent firm that matters, but the tax difference vis-a-vis the subsidiary facing the lowest tax rate within the group.

\section{Technical Appendix not intended for pub- lication}

This appendix explains in detail the structure of the model used in the above comment, and provides a detailed derivation of the optimal leverage ratios therein.

Assume that a multinational firm (MNC) owns affiliates in $i=1, \ldots, n$ countries and is itself located in country $p$. Each affiliate produces a homogenous good according to the production function $y_{i}=f\left(A_{i}\right)$, using capital $A_{i}$ as the only input. Rental costs of capital are exogenous (small country assumption) and equal to $r$. Capital $A_{i}$ is financed either by equity $I_{i}$, external (third party) debt $L_{i}$ or internal debt $\hat{L}_{i}$, the latter stemming from related affiliates. Thus, the balance sheet of affiliate $i$ reads

$$
A_{i}=I_{i}+L_{i}+\hat{L}_{i}
$$

Following Huizinga, Laeven and Nicodème (2008) (henceforth HLN), we will assume that the level of capital $A_{i}$ is fixed in any affiliate and that the

${ }^{9}$ This is, e.g., the case when both the subsidiary and the parent belong to an EU country. Repatriated dividends are tax exempt in the parent country while interests received are subject to the ordinary corporate income tax. 
MNC will adjust its equity if there is a change in the level of debt, $\triangle I_{i}=$ $-\triangle\left(L_{i}+\hat{L}_{i}\right)$. Without loss of generality, we assume that all affiliates are directly owned by the parent MNC and that its outside assets are zero, $A_{p}=0$. The balance sheet of the MNC, accordingly, reads

$$
\sum_{i \neq p} I_{i}=E_{p}+L_{p}+\hat{L}_{p}
$$

Debt causes additional costs both in an affiliate and - as bankruptcy costs in case of bail outs of affiliates - in the whole MNC. As internal debt is in fact more like tax-deductible equity than debt, ${ }^{10}$ we are going to assume that the cost functions of external and internal debt are separable. All cost functions are assumed to be convex in the leverage ratios, but proportional in capital employed.

In external debt, there are some profits from, e.g., mitigating informational asymmetries and therefore from dampening moral hazard effects of managers, but there are also costs involved, e.g., due to inducing too riskaverse behavior or bankruptcy costs on the affiliate level. Hence, we assume that there is an optimal leverage ratio $\lambda^{*}$ in absence of taxation (trading pro and cons of external debt) in each affiliate. According to HLN, the cost function of external debt is assumed to be

$$
C\left(\lambda_{i}\right)=\frac{\mu}{2} \cdot\left(\lambda_{i}-\lambda^{*}\right)^{2} \cdot A_{i}-\frac{\mu}{2} \cdot\left(\lambda^{*}\right)^{2} \cdot A_{i},
$$

where $\lambda_{i}=\frac{L_{i}}{A_{i}}$ represents the leverage ratio in external debt in affiliate $i$.

Internal debt costs accrue due to circumventing thin-capitalization and controlled-foreign-company rules or to hire lawyers etc to hide the true nature the balance. If there is no internal debt or if the affiliate is an internal lender,

${ }^{10}$ In line with this Chowdhry and Coval (1998) pp. 87f, and Stonehill and Stitzel (1969) argue that internal debt should in fact be seen as tax-favored equity. 
no costs accrue. The cost function is given by

$$
\begin{array}{ll}
\hat{C}\left(\hat{\lambda}_{i}\right)=\frac{\eta}{2} \cdot\left(\hat{\lambda}_{i}\right)^{2} \cdot A_{i}, & \text { if } \quad \hat{\lambda}_{i}>0, \\
\hat{C}\left(\hat{\lambda}_{i}\right)=0, & \text { if } \quad \hat{\lambda}_{i} \leq 0,
\end{array}
$$

where $\hat{\lambda}_{i}=\frac{\hat{L}_{i}}{A_{i}}$ represents the leverage ratio in internal debt in affiliate $i$. Note that there is no reason why $\eta$ should be equal to $\mu$ in equation (11), as internal and external debt are different in nature and therefore their associated costs should differ as well.

Analogously to HLN, the MNC is willing to bail out any affiliate, which is going bankrupt. Thus, bankruptcy costs depend on the firm-wide leverage ratio in external debt, $\lambda_{f}$, across all affiliates. This overall leverage ratio is defined as $\lambda_{f}=\frac{\sum_{i} L_{i}}{\sum_{i} A_{i}}$., and total bankruptcy costs are given by

$$
C_{f}=\frac{\gamma}{2} \cdot \lambda_{f}^{2} \cdot \sum_{i} A_{i}=\frac{\gamma}{2} \cdot \frac{\left(\sum_{i} L_{i}\right)^{2}}{\sum_{i} A_{i}}
$$

In order to make clear how HLN implicitly invoke symmetry assumptions on withholding taxes it is useful to lay out a proper microfoundation for taxation. Let economic profits in affiliate $i$ before any taxation be

$$
\pi_{i}^{e}=f\left(A_{i}\right)-r \cdot A_{i}-C\left(\lambda_{i}\right)-\hat{C}\left(\hat{\lambda}_{i}\right)
$$

According to most real-world tax systems and in line with HLN, we assume that rental costs of equity are not tax deductible. Moreover, neither costs of external debt nor cost of internal debt are assumed to be deductible from the corporate tax base. This does not have any qualitative effect on the results and corresponds to the modeling in HLN. Hence, taxable profits are given as

$$
\pi_{i}^{t}=f\left(A_{i}\right)-r \cdot\left(L_{i}+\hat{L}_{i}\right)
$$


Put together, an affiliate's profit after corporate taxation in country $i$ is

$$
\pi_{i}=\underbrace{\pi_{i}^{e}-t_{i} \cdot \pi_{i}^{t}}_{=V_{i}^{L}}=\underbrace{\left(1-t_{i}\right) \cdot f\left(A_{i}\right)-r \cdot A_{i}}_{=V_{i}^{U}}+t_{i} \cdot r \cdot\left(L_{i}+\hat{L}_{i}\right)-C\left(\lambda_{i}\right)-\hat{C}\left(\hat{\lambda}_{i}\right),
$$

where $t_{i}$ is the (statutory) corporate tax rate in country $i$, and $V_{i}^{L}$ and $V_{i}^{U}$ are the values of a leveraged and a completely unleveraged affiliate in country $i$. An important point and a major distinction to the set-up in HLN is to note from the above equation that the affiliate specific costs of external and internal debt, $C\left(\lambda_{i}\right)$ and $\hat{C}\left(\hat{\lambda}_{i}\right)$, do reduce the amount of dividends $\left(\pi_{i}\right)$ that can be paid out.

In a static one-period model as the one used by HLN, the value of a firm $\left(V^{L}\right)$ and the firm's after tax profit $\left(\Pi_{p}\right)$ are identical. Thus, total profits of the MNC, $\Pi_{p}=V^{L}$, can be calculated by summing up profits across all affiliates, taking into account potential double taxation by impure tax credits, withholding taxes, etc., and deducting MNC-wide bankruptcy $\operatorname{costs} C_{f}$. Following HLN, repatriated dividends $\pi_{i}$ can be subject to a nonresident withholding tax $\left(w_{i}^{e}\right)$, the parent tax rate $t_{p}$ on repatriated dividends (adjusted possibly for various credit schemes) and the corporate tax rate $t_{i}$. In HLN $\tau_{i}$ is the effective tax rate on dividends and encompasses different combinations of $w_{i}^{e}, t_{p}$ and $t_{i}$ depending on the system for taxing repatriated dividends. ${ }^{11}$ Our set up, however, has made it clear that the corporate tax rate $t_{i}$ cannot be part of the effective tax rate on repatriated income. We will nevertheless use $\tau_{i}$ to denote the effective after tax rate on dividends,

\footnotetext{
${ }^{11}$ See e.g., page 87 where under the deduction system $\tau_{i}=1-\left(1-t_{p}\right)\left(1-w_{i}^{e}\right)\left(1-t_{i}\right)$.
} 
but $\tau_{i}$ is a function of $t_{p}$ and $w_{i}^{e}$ only. Then,

$$
\begin{aligned}
\Pi_{p} & =V^{L}=\sum_{i} \tau_{i} \cdot \pi_{i}-C_{f} \\
& =\underbrace{\sum_{i} \tau_{i} \cdot\left\{\left(1-t_{i}\right) f\left(A_{i}\right)-r \cdot A_{i}\right\}}_{=V^{U}} \\
& +\sum_{i} \tau_{i} \cdot\left\{t_{i} \cdot r \cdot\left(L_{i}+\hat{L}_{i}\right)-C\left(\lambda_{i}\right)-\hat{C}\left(\hat{\lambda}_{i}\right)\right\}-C_{f}\left(\lambda_{f}\right) .
\end{aligned}
$$

Note that the overall sum of lending and borrowing in internal debt and therefore the total internal interest payments across all affiliates must be equal to zero. The reason is that at least one affiliate must be a lender which will receive all the interest paid on internal debt by other affiliates. Consequently,

$$
\sum_{i} r \cdot \hat{L}_{i}=0
$$

Relying on equations (11), (13) and (17) as well as taking into account the restriction on internal debt in (18), the optimization problem can be stated as

$$
\begin{aligned}
\max _{L_{i}, \hat{L}_{i}} \Pi_{p} & =\sum_{i} \tau_{i}\left\{\left(1-t_{i}\right) f\left(A_{i}\right)-r \cdot A_{i}+t_{i} \cdot r \cdot\left(L_{i}+\hat{L}_{i}\right)\right. \\
& \left.-\frac{\mu}{2} \cdot\left(\frac{L_{i}}{A_{i}}-\lambda^{*}\right)^{2} \cdot A_{i}-\frac{\mu}{2} \cdot\left(\lambda^{*}\right)^{2} \cdot A_{i}-\hat{C}\left(\hat{\lambda}_{i}\right)\right\}-\frac{\gamma}{2} \cdot \frac{\left(\sum_{i} L_{i}\right)^{2}}{\sum_{i} A_{i}} \\
\text { s.t. } & \sum_{i} r \cdot \hat{L}_{i}=0,
\end{aligned}
$$


where $\hat{\lambda}_{i}=\frac{\hat{L}_{i}}{A_{i}}$. The resulting first order conditions are

$$
\begin{array}{r}
\tau_{i}\left\{t_{i} \cdot r-\mu \cdot\left(\frac{L_{i}}{A_{i}}-\lambda^{*}\right)\right\}-\gamma \cdot \frac{\sum_{i} L_{i}}{\sum_{i} A_{i}}=0 \\
\tau_{i} \cdot\left\{t_{i} \cdot r-\hat{C}^{\prime}\left(\hat{\lambda}_{i}\right) \cdot \frac{1}{A_{i}}\right\}-m \cdot r=0
\end{array}
$$

where $m$ represents the Lagrangian multiplier.

From (20) we derive

$$
\frac{\hat{C}^{\prime}\left(\hat{\lambda}_{i}\right)}{A_{i}}=r \cdot \frac{\tau_{i} \cdot t_{i}-m}{\tau_{i}}>0
$$

and, consequently,

$$
m=\min _{i} t_{i}^{e}=\tau_{i} \cdot t_{i}=\tau_{1} \cdot t_{1},
$$

assuming that affiliate 1 has the lowest effective tax rate $t_{i}^{e}$. Equation (23) follows from (22) and the fact that $\hat{C}^{\prime}\left(\hat{\lambda}_{i}\right) \geq 0, \forall \lambda_{i}$. In sum thuis implies that $\hat{L}_{i}>0$ in all affiliates $i>1$. From (18) it follows that $\hat{\lambda}_{1}=-\frac{\sum_{i>1} \hat{L}_{i}}{A_{1}}<0$. Moreover, we have

$$
\frac{\hat{C}^{\prime}}{A_{i}}=\eta \cdot \frac{\hat{L}_{i}}{A_{i}}=\eta \cdot \hat{\lambda}_{i}, \quad \forall i>1
$$

from applying equation (12). Accordingly, from (22) and (23) the optimal internal leverage ratio in affiliate $i>1$ reads

$$
\hat{\lambda}_{i}=\frac{r}{\eta} \cdot \frac{\tau_{i} \cdot t_{i}-\tau_{1} \cdot t_{1}}{\tau_{i}}, \forall i>1
$$

Turning to equation (5), rearranging it yields

$$
\tau_{i} \cdot \mu \cdot \lambda_{i}=\tau_{i} \cdot \mu \cdot \lambda^{*}+\tau_{i} \cdot t_{i} \cdot r-\gamma \lambda_{i} \cdot \rho_{i}-\gamma \cdot \sum_{j \neq i} \lambda_{j} \cdot \rho_{j}
$$

where $\rho_{i}=\frac{A_{i}}{\sum_{i} A_{i}}$. Subtracting equation (5), evaluated for affiliate $j$, from 
equation (5), evaluated for affiliate $i$, we obtain

$$
\lambda_{j}=\frac{\tau_{i}}{\tau_{j}} \cdot \lambda_{i}-\frac{\tau_{i} \cdot t_{i}-\tau_{j} \cdot t_{j}}{\tau_{j} \cdot \mu} \cdot r+\frac{\tau_{i}-\tau_{j}}{\tau_{j}} \cdot \lambda^{*} .
$$

Applying (27) in (26), we have

$$
\begin{aligned}
\tau_{i} \cdot \mu \cdot \lambda_{i} & =\tau_{i} \cdot \mu \cdot \lambda^{*}+\tau_{i} \cdot t_{i} \cdot r-\gamma \cdot \lambda_{i} \cdot \rho_{i} \\
& +\gamma \cdot \sum_{j \neq i} \frac{\tau_{i} \cdot t_{i}-\tau_{j} \cdot t_{j}}{\tau_{j} \cdot \mu} \cdot r \cdot \rho_{j} \\
& -\gamma \cdot \sum_{j \neq i} \frac{\tau_{i}}{\tau_{j}} \cdot \lambda_{i} \cdot \rho_{j}-\gamma \cdot \sum_{j \neq i} \frac{\tau_{i}-\tau_{j}}{\tau_{j}} \cdot \lambda^{*} \cdot \rho_{j} .
\end{aligned}
$$

It is now fairly obvious that there is no easy way to simplify this expression in order to solve it for an explicit optimal leverage ratio $\lambda_{i}$ of external debt. It is straightforward to show that only if $\tau_{i}=\tau_{j}, i \neq j$, can we reproduce the rearranged first order condition (5) in HLN, which is used as a basis for the regression equation (6) in HLN. This is not an innocent assumption since it effectively amounts to assuming that all countries employ the same effective tax on repatriated dividends, i.e the sum of the withholding tax and the home country tax on repatriated dividends must be the same across countries. Invoking this symmetry $\tau_{i}=\tau_{j}=\tau$, equation (27) reduces to

$$
\lambda_{j}=\lambda_{i}-\frac{t_{i}-t_{j}}{\mu} \cdot r
$$

and equation (28) simplifies to

$$
\begin{aligned}
\tau \cdot \mu \cdot \lambda_{i} & =\tau \cdot \mu \cdot \lambda^{*}+\tau \cdot t_{i} \cdot r-\gamma \cdot \lambda_{i} \cdot \rho_{i} \\
& -\gamma \cdot \lambda_{i} \cdot \sum_{j \neq i} \rho_{j}+\gamma \cdot \sum_{j \neq i} \frac{t_{i}-t_{j}}{\mu} \cdot r \cdot \rho_{j} .
\end{aligned}
$$


Recall that

$$
\sum_{j \neq i} \rho_{j}=\sum_{j \neq i} \frac{A_{j}}{\sum_{i} A_{i}}=\frac{\sum_{i} A_{i}-A_{i}}{\sum_{i} A_{i}}=1-\frac{A_{i}}{\sum_{i} A_{i}}=1-\rho_{i} .
$$

By substituting equation (31) into (30), collecting all terms with a $\lambda_{i}$ on the LHS and slightly rearranging, we end up with

$$
\begin{aligned}
\lambda_{i} & =\frac{\tau \cdot \mu}{\tau \cdot \mu+\gamma} \cdot \lambda^{*}+\frac{r}{\tau \cdot \mu+\gamma} \cdot \tau \cdot t_{i} \\
& +\frac{\gamma \cdot r}{\tau \cdot \mu+\gamma} \cdot \sum_{j \neq i}\left(t_{i}-t_{j}\right) \cdot \rho_{j} .
\end{aligned}
$$

Applying the definitions given on page 95 in $\mathrm{HLN}$ for $\beta_{k}, k=0,1,2$, and correcting these for the proper effective withholding tax term, we have $\beta_{0}=\frac{\tau \cdot \mu}{\tau \cdot \mu+\gamma}, \beta_{1}=\frac{1}{\tau \cdot \mu+\gamma}$ and $\beta_{2}=\frac{\gamma}{\tau \cdot \mu+\gamma}$. Then, equation (32) becomes

$$
\lambda_{i}=\beta_{0} \cdot \lambda^{*}+\beta_{1} \cdot r \cdot \tau \cdot t_{i}+\beta_{2} \cdot r \cdot \sum_{j \neq i}\left(t_{i}-t_{j}\right) \cdot \rho_{j},
$$

which corresponds to equation (5) in HLN, if we set the interest rate $r=1$, an assumption they implicitly invoke.

Adding the optimal leverage ratio of internal debt (25), defining $\beta_{3}=\frac{1}{\eta}$ and using $\tau_{i}=\tau_{j}=\tau$ again, the total leverage ratio $b_{i}$ of an affiliate $i>1$ is

$$
\begin{aligned}
b_{i} & =\lambda_{i}+\hat{\lambda}_{i} \\
& =\beta_{0} \cdot \lambda^{*}+\beta_{1} \cdot r \cdot \tau \cdot t_{i}+\beta_{2} \cdot r \cdot \sum_{j \neq i}\left(t_{i}-t_{j}\right) \cdot \rho_{j} \\
& +\beta_{3} \cdot r \cdot\left[t_{i}-t_{1}\right], \quad \forall i>1 .
\end{aligned}
$$

The total leverage ratio in affiliate 1 , acting as internal bank, is instead 
given by

$$
\begin{aligned}
b_{1} & =\lambda_{1}+\hat{\lambda}_{1} \\
& =\beta_{0} \cdot \lambda^{*}+\beta_{1} \cdot r \cdot \tau \cdot t_{1}+\beta_{2} \cdot r \cdot \sum_{j \neq 1}\left(t_{1}-t_{j}\right) \cdot \rho_{j}-\frac{\sum_{i>1} \hat{L}_{i}}{A_{1}}
\end{aligned}
$$

where $\hat{\lambda}_{1}=-\frac{\sum_{i>1} \hat{L}_{i}}{A_{1}}$ in order to fulfill the constraint on internal interest payments (18).

\section{References}

Büttner, T., and G. Wamser, 2007. Intercompany Loans and Profit Shifting - Evidence from Company-Level Data. CESifo Working Paper Nr. 1959, Munich.

Büttner, T., M. Overesch, U. Schreiber, and G. Wamser, 2006. Taxation and Capital Structure Choice - Evidence from a Panel of German Multinationals. CESifo Working Paper Nr. 1841, Munich.

Chowdhry, B., and J.D. Coval, 1998. Internal Financing of Multinational Subsidiaries: Debt vs. Equity. Journal of Corporate Finance 4, 87-106.

Desai, M.A., C.F. Foley, and J.R. Hines, 2004. A Multinational Perspective on Capital Structure Choice and Internal Capital Markets. Journal of Finance 59, 2451-2487.

Huizinga, H, L. Laeven, and G. Nicodème, 2008. Capital Structure and International Debt-Shifting. Journal of Financial Economics 88, 80118.

Lechoor, C. and J. Mintz, 1993. On the taxation of multinational corporate investment when the deferral method is used by the capital exporting country. Journal of Public Economics 51, 75-96. 
Mintz, J., and M. Smart, 2004. Income Shifting, Investment, and Tax Competition: Theory and Evidence from Provincial Taxation in Canada. Journal of Public Economics 88, 1149-1168.

Mintz, J., and A.J. Weichenrieder, 2005. Taxation and the Financial Structure of German outbound FDI. CESifo Working Paper Nr. 1612, Munich

Sinn, H.-W., 1987. Capital Income Taxation and Resource Allocation. Elsevier, Amsterdam.

Stonehill, A., and Stitzel, T., 1969. Financial Structure and Multinational Corporations. California Management Review 12, 91-96. 